mansasa

glyndŵn

Glyndŵr University

Glyndŵr University Research Online

9-1-2009

\title{
Isolation and Rheological Characterization of Mucuna flagellipes Seed Gum
}

Louis M. Nwokocha

Peter A. Williams

Glyndwr University, p.a.williams@glyndwr.ac.uk

Follow this and additional works at: http://epubs.glyndwr.ac.uk/cwsp

Part of the Polymer Chemistry Commons

The article was published by Elsevier and can be found at www.sciencedirect.com Copyright (C) 2008 Elsevier Ltd

\section{Recommended Citation}

Nwokocha, L.M., \& Williams, P.A. (2009) 'Isolation and rheological characterization of Mucuna flagellipes seed gum'. Food Hydrocolloids, 23(5), 1394-1397

This Article is brought to you for free and open access by the Materials Science at Glyndwir University Research Online. It has been accepted for inclusion in Centre for Water Soluble Polymers by an authorized administrator of Glyndŵr University Research Online. For more information, please 


\title{
Isolation and Rheological Characterization of Mucuna flagellipes Seed Gum \\ Louis. M. Nwokocha ${ }^{1}$ and Peter. A. Williams ${ }^{2}$ \\ ${ }^{1}$ Department of Chemistry, University of Ibadan, Ibadan, Nigeria \\ ${ }^{2}$ Center for Water Soluble Polymers, Glyndwr University, Wrexham, LL11 2AW, UK
}

\begin{abstract}
The gum from M. flagellipes seed endosperm has been isolated and characterised using capillary viscometry and steady shear and small deformation oscillatory rheometry. The endosperm was found to constitute $67.15 \%$ of the whole seed and yielded $32.6 \%$ of gum. The Huggins and Kraemer plots obtained by capillary viscometry gave an intrinsic viscosity of $7.9 \mathrm{dL} / \mathrm{g}$ and viscosity average molecular mass was calculated to be $2.1 \times 10^{6}$ using the Mark Houwink relationship. The zero shear viscosity was plotted against the coil overlap parameter, $\mathrm{C}[\eta]$, and the slopes of the lines in the dilute and semi-dilute regions were found to be $\sim 1.0$ and 4.6 respectively. The curves were fitted to the Tuinier and Martin equations and showed only qualitative agreement. The shear flow viscosity profiles indicated that $M$. flagellipes gum did not exhibit significant shear thinning at polymer concentrations less than $0.5 \%$, however, at higher concentrations, pronounced shear thinning was observed with the relaxation time $(\tau)$ increasing with increase in polymer concentration. The dynamic viscosity profiles showed that at all polymer concentrations examined, a Newtonian plateau was obtained at low frequencies indicating that the loss modulus was the dominant response. Plots of $\log \eta$ versus $\log \check{\gamma}$ and $\log \eta^{*}$ versus $\log \omega$ were not superimposible and hence did not obey the Cox-Merz rule.
\end{abstract}


Key words: Mucuna flagellipes, seed gum, isolation, rheological properties

\section{INTRODUCTION}

Vegetable gums are commonly used in food manufacturing processes as viscosifying agents. Many plants have been chemically analyzed for their potential as sources of seed

gums. These include guar with 19-43\% gum (Undersander, et al, 1991), Cassia brewsteri with $33.7 \pm 0.4 \%$ gum (Cunningham and Walsh, 2002) and mesquite with $24.9 \%$ gum (Estevez et al, 2004). Mucuna flagellipes is indigenous to West Africa and belongs to the family leguminosae and subfamily papilionaceae. The plant is an annual crop and a climber and can be cultivated more than once a year. It is high yielding; and bears pods which contain usually three to four seeds per pod. The seeds are usually dark brown to black, sometimes speckled, depending on variety. Among the natives, the endosperm which is rich in gum is pulverized and used as thickener in many traditional food preparations. Several authors have reported on its suitability for application in processed foods including use as a rheology modifier (Onweluzo et al, 1999), stabilizer (Onweluzo et al,1995, Onweluzo et al, 2004) and film former (Ojile et al, 2000). Mucuna gum is a galactomannan and has D-galactose and D-mannose as the main sugars (Onweluzo et al, 1995; Srivastava and Kapoor, 2005). However, we are yet to find reports on the proportion of gum in the seed or on its intrinsic viscosity, molecular mass and rheological properties. 


\section{MATERIALS AND METHODS}

Isolation of seed gum: M. flagellipes seeds were dehulled to obtain the seed endosperms (Figure 1). The endosperms were pulverized by means of a hammer mill and the flour obtained by passing through a $500 \mu \mathrm{m}$ sieve and dried in the oven at $80^{\circ} \mathrm{C}$ for $6 \mathrm{hr}$. The flour was defatted by extracting with hexane in a soxhlet extractor for $6 \mathrm{hr} .5 \mathrm{~g}$ of sample was dispersed in $400 \mathrm{ml}$ distilled water and hydrated continuously by means of a magnetic stirrer (FBI 15001, Fischer Scientific, UK) for $6 \mathrm{hr}$. This was poured into centrifuge tubes and centrifuged at $2500 \mathrm{rpm}$ for $30 \mathrm{~min}$. The supernatant was poured into a large beaker. The residue was reconstituted repeatedly with fresh distilled water, stirred and centrifuged again. The supernatant was pooled together and treated with 2-propanol when the gum spooled out. The clear liquor was decanted while the trapped solvent was removed by filtering under suction in a Buchner funnel. The crude gum was re-dissolved in fresh distilled water and re-precipitated with 2-propanol. The gum sample was dried in a convention oven at $60^{\circ} \mathrm{C}$ overnight and cooled in a desiccator. This was pulverized in a mortar and stored in a sealed container. The gum preparation was carried out in triplicate. Elemental analysis: The elemental analysis was done with a Carlo-Erba CHN analyser. The sample was initially combusted in oxygen, subjected to chromatography (GC-MS) and the component elements quantified with a thermal conductivity detector. Calibration was done using least squares to linear fit.

Intrinsic viscosity: The intrinsic viscosity of $M$. flagellipes gum was determined in distilled water. The gum solution was prepared by dispersing $50 \mathrm{mg}$ of the gum ( $\mathrm{db}$, dry basis) in $100 \mathrm{~mL}$ of the distilled water at room temperature and placing on a roller mixer (SRT2, Staurt Scientific) overnight. $2 \mathrm{~mL}$ of solution was transferred into a Cannon- 
Ubbelohde capillary viscometer (No 75) which was immersed in a precision water bath to maintain the temperature at $25.0 \pm 0.1{ }^{\circ} \mathrm{C}$ and after equilibration for 10 minutes, the flow time was determined between the two etched marks. Serial dilution was performed in situ and three readings were taken for each dilution and averaged. The viscosity average molecular mass, $\mathbf{M}_{\mathrm{w}}$ was evaluated using the Mark-Houwink equation (Lazaridou et al, 2000) (equation 1).

$$
[\eta]=80.2 \times 10^{-6} \times M_{w}^{0.79}
$$

Rheological characterization of $M$. flagellipes gum: Different concentrations of the $M$. flagellipes gum solutions $(0.1 \%, 0.2 \%, 0.5 \%, 1.0 \%, 2.0 \%$ and $3.0 \%)$ were prepared by dispersing the desired amount of dry gum powder in distilled water and leaving to tumble overnight at ambient temperature using a roller mixer to ensure complete hydration (SRT2, Stuart Scientific, UK). Steady shear viscosity and small deformation oscillation experiments were performed using a Controlled Stress Rheometer (AR 2000, TA Instruments) fitted with cone and plate geometry $\left(60 \mathrm{~mm} 2^{\circ}\right.$ steel cone, $50 \mu \mathrm{m}$ gap). The flow properties were obtained at $25^{\circ} \mathrm{C}$ by subjecting the gum solutions to stepped-flow at a shear rate of $10^{-3}$ to $10^{3} \mathrm{~s}^{-1}$ after pre-conditioning. In the small deformation oscillation experiments, stress sweeps were performed on each gum solution to locate the linear viscoelastic region. A frequency sweep was performed on the gum solutions in the region of $10^{-1}$ to $120 \mathrm{rad} / \mathrm{s}$ at an amplitude strain within the linear viscoelastic region.

\section{RESULTS AND DISCUSSION}


Composition: Table 1 shows the physical composition of $M$. flagellipes seed. The endosperm constituted $46.73-74.76 \%$ of whole seed with mean of $67.15 \%$. The hull was easily separable from the endosperm by mechanical means. There was no visible germ. The defatted endosperm yielded $32.6 \pm 1.97 \%$ of gum (Table 1). Elemental analysis showed the gum contained $1.87 \%$ nitrogen, $39.25 \%$ carbon and $6.43 \%$ hydrogen. This is the first available data on M. flagellipes gum and values are in the range of those reported for other sources of galactomannan (Undersander, et al, 1991, Cunningham and Walsh, 2002).

Intrinsic viscosity: Figure 2 shows the Huggins and Kraemer plot for M. flagellipes gum and the intrinsic viscosity of $M$. flagellipes obtained from the intercept was $7.9 \mathrm{dL} / \mathrm{g}$. Application of the Mark-Houwink equation gave a viscosity average molecular mass of $2.1 \times 10^{6}$ which is similar to the viscosity average molecular mass values reported for other galactomannans such as carob gum (Lazaridou et al, 2000).

The double logarithmic plot of zero shear specific viscosity, $\eta_{\mathrm{sp}, \mathrm{o}}$, against the coil overlap


the lines below and above $C^{*}$ were $\sim 1.0$ and 4.6 respectively. This compares to values of $\sim 4 /[\eta]$ for $C^{*}$ and 1.4 and to 3.3 for the slopes of the lines for a range of random coil polysaccharides (Morris et al, 1981). Slopes of $\sim 1$ in the dilute region have been reported for Aeromonas polysaccharide (Xu et al, 2006), the exopolysaccharide from Escherichia coli strain S61 (Ren et al, 2003) and acid hydrolyzed amioca starch (Chamberlain and Rao, 2000). A higher value for the slope in the semi-dilute region has been reported for other polysaccharides. Kapoor et al (1998) have reported slope of 5.87 for Cassia spectabilis galactomannan . Andrade et al (1999) reported $C^{*}=3.3 /[\eta]$ for 
galactomannans from Caesalpinia pulcherrima and Cassia javanica. The data were also fitted to the equations proposed by Tuinier et al, (equation 2) and Martin (equation 3) and curves obtained are shown in Figure 3b.

$$
\begin{gathered}
\eta_{s p, o}=c[\eta]_{o}+\frac{1}{25}\left([\eta]_{o} c\right)^{\frac{7}{2}} \\
\eta_{s p, o}=c[\eta]_{o} \exp \left(k_{m} c[\eta]_{o}\right)
\end{gathered}
$$

where $k_{m}$ is Martin polymer-polymer interaction parameter.

Both models showed only qualitative agreement as has been reported by Ratcliffe et al, (2005) for glucomannan.

\section{Steady shear viscosity and viscoelastic properties}

Figure 4 shows the steady shear viscosity as a function of shear rate for different concentrations of $M$. flagellipes gum. The flow profiles indicate that $M$. flagellipes gum exhibited Newtonian behaviour at polymer concentrations less than $0.5 \%$. At higher concentrations, above $\mathrm{C}^{*}$, the polymer solutions became more viscous and exhibited nonNewtonian behaviour with marked shear thinning observed. Table 3 shows the values of the various parameters obtained by fitting the data to the Cross (equation 4) and Newtonian models (equation 5)

$$
\text { Cross : } \frac{\eta-\eta_{\infty}}{\eta_{o}-\eta_{\infty}}=\frac{1}{1+\left(\tau^{*} \dot{\gamma}\right)^{m}}
$$

Newtonian $: \eta=\sigma / \dot{\gamma}$ 
Where $\eta, \eta_{\mathrm{o}}$ and $\eta_{\infty}$ are viscosity (Pa.s), zero shear viscosity (Pa.s) and infinite shear viscosity (Pa.s) respectively, $\dot{\gamma}$ is shear rate $\left(\mathrm{s}^{-1}\right), \tau$ is relaxation time (s) and $\mathrm{m}$ is the rate index (dimensionless) and $\sigma$ is shear stress $(\mathrm{Pa})$. The relaxation time, $\tau\left(\tau=1 / \bar{\mho}_{\text {crit, }}, \bar{\gamma}_{\text {crit }}=\right.$ critical shear rate, marks the onset of shear thinning), increased with increase in polymer concentration.

The variation of the storage modulus $\left(\mathrm{G}^{\prime}\right)$, loss modulus $\left(\mathrm{G}^{\prime \prime}\right)$ and complex shear viscosity $\left(\eta^{*}\right)$ with the frequency of oscillation $(\omega)$ for the gum solutions are shown in Figures 5 and 6 . In Figure 5, the gum at $1.0 \%$ concentration gave a predominantly viscous response $\left(\mathrm{G}^{\prime \prime}>\mathrm{G}^{\prime}\right)$, however at concentrations of $2.0 \%$ and $3.0 \%$, there was a transition from a predominantly viscous response at long timescales of measurement $\left(G^{\prime \prime}>G^{\prime}\right)$ to a predominantly elastic response at shorter timescales $\left(\mathrm{G}^{\prime}>\mathrm{G}^{\prime \prime}\right)$. This cross over point occurred at $\omega=9.087 \mathrm{rad} / \mathrm{s}$ in $3.0 \%$ and $\omega=30.62 \mathrm{rad} / \mathrm{s}$ in $2.0 \%$ while the corresponding $\mathrm{G}^{\prime}$ are $72.24 \mathrm{~Pa}$ and 41.96 $\mathrm{Pa}$ respectively. The average timescales for microstructural coupling estimated from the crossover point of the moduli (given by $1 / \omega$, where $G^{\prime}=G^{\prime \prime}$ ) for $2 \%$ and $3 \%$ gum solutions were $0.03 \mathrm{~s}$ and 0.11 s respectively. In Figure $6, \eta^{*}$ exhibited a Newtonian plateau at low $\omega$ indicating that the loss modulus was the dominant response at all gum concentrations.

Figure 7 shows the steady shear viscosity (log $\eta$ versus $\log \check{y})$ and dynamic viscosity $(\log$ $\eta^{*}$ versus $\left.\log \omega\right)$ of the solutions at varying concentration. It was noted that the two sets of curves did not superimpose at any of the concentrations in contradiction to the CoxMerz rule. Such behaviours has been observed for other polysaccharides including konjac glucamannan (Ratcliffe et al, 2005) and Aeromonas gum (Xu et al, 2006) and has been 
attributed to weak association between the polymer chains, so-called hyperentanglements.

\section{References}

Andrade, C.T., Azero, E.G., Luciano, L. and Goncalves, P. (1999). Solution properties of the galactomannans extracted from the seeds of Caesalpinia pulcherrima and Cassia javanica: comparison with locust bean gum. International Journal of Biological Macromolecules 26 (2-3): 181-185.

Chamberlain, E.K. and Rao, M.A. (2000). Effect of concentration on the rheological properties of acid-hydrolyzed amylopectin solutions. Food Hydrocolloids 14, 163-171. Cunningham, D.C. and Walsh, K.B. (2002). Galactomannan content and composition in Cassia brewsteri seed. Australia Journal of Experimental Agriculture, 42(8): 1081-1086. Estevez, A.M., Saenz, C., Hurtado, M.L., Escobar, B., Espinoza, S. and Suarez, C. (2004). Extraction methods and some physical properties of mesquite (Prosopis chilensis (Mol) Stuntz) seed gum. Journal of the Science of Food and Agriculture, 84(12): 14871492.

Hwang, J.K. and Shin, H.H. (2000). Rheological properties of chitosan solutions. KoreaAustralia Rheology Journal 12 (3\&4), 175-179.

Kapoor, V.P., Taravel, F.R., Joseleau, J-P., Milas, M., Chanzy, H. and Rinaudo, M. (1998). Cassia spectabilis DC seed galactomannan: structural, crystallographical and rheological studies. Carbohydrate Research, 306(1): 231-241. 
Lazaridou, A., Biliaderis, C.G. and Izydorczyk, M.S. (2000). Structural characterization and rheological properties of locust bean galactomannans: a comparison of samples from different carob tree populations. Journal Science of Food and Agriculture, 81: 68-75.

Launay, B., Doublier, J.I., and Cuvelier, G. (1986). Flow properties of aqueous solutions and dispersions of polysaccharides. In: J.R. Mitchell and D.A. Ledward (Eds.), Functional Properties of Food Macromolecules (pp1-78). London, Elsevier Applied Science Publishers.

Morris, E.R., Cutler, A.N., Ross-Murphy, S.B., Rees, D.A. and Price, J. (1981).

Concentration and shear rate dependence of viscosity in random coil polysaccharide solutions. Carbohydrate Polymers 1, 5-21.

Ojile, J.E., Adikwu, M. and Okoli, N.D. (2000). Properties of films from prosopis and mucuna gums. Boll Chim Farm, 139(4): 190-3.

Onweluzo, J.C., Leelavathi, K. and Rao, P.H. (1995). Effect of Detarium microcarpum (Dm) and Mucuna flagellipes (Mf) gums on the quality of white bread. Plants Food for Human Nutrition, 54(2): 173-82.

Onweluzo, J.C., Obanu, Z.A. and Okwandu, M.C. (2004). Potentials of Gum from Detarium microcarpum (DM) and Mucuna flagellipes (MF) Seeds as Raw Beef Burger Stabilizers. Plants Food for Human Nutrition, 59(4): 137-141.

Onweluzo, J.C., Onuoha, K.C. and Obanu, Z.A. (1995). Certain functional properties of gums derived from lesser known tropical legumes (Afzelia africana, Detarium microcarpum and Mucuna flagellipes). Plants Food for Human Nutrition, 48(1): 55-63. Ratcliffe, I., Williams, P.A., Viebke, C. and Meadows, J. (2005). Physicochemical characterization of konjac glucomannan. Biomacromolecules 6, 1977-1986. 
Ren, Y., Ellis, P.R., Sutherland, I.W. and Ross-Murphy, S.B. (2003). Dilute and semidilute solution viscosity solution properties of an exopolysaccharide from Escherichia coli strain S61. Carbohydrate Polymers 52, 189-195.

Srivastava, M. and Kapoor, V.P. (2005). Seed galactomannans: An overview. Chemistry and Biodiversity, 2 (3): 295-317.

Undersander, D.J., Putnam, D.H., Kaminski, A.R., Kelling, K.A., Doll, J.D., Oplinger, E.S. and Gunsolus, J.L. (1991). Guar. Alternative Field Crops Manual, http://www.hort.purdue.edu/newcrop/afcm/guar.html Velez, G., Fernandez, M.A., Munoz, J., Williams, P.A.and English, R.J. (2003). Role of hydrocolloids in the creaming of oil in water emulsions. Journal of Agriculture and Food Chemistry, 51(1): 265-269

Xu, X., Liu, W. and Zhang, L. (2006). Rheological behavior of Aeromonas gum in aqueous solutions. Food Hydrocolloids 20(5): 723-729.

The authors acknowledge funding support of the University of Ibadan MacArthur Foundation Grant. 


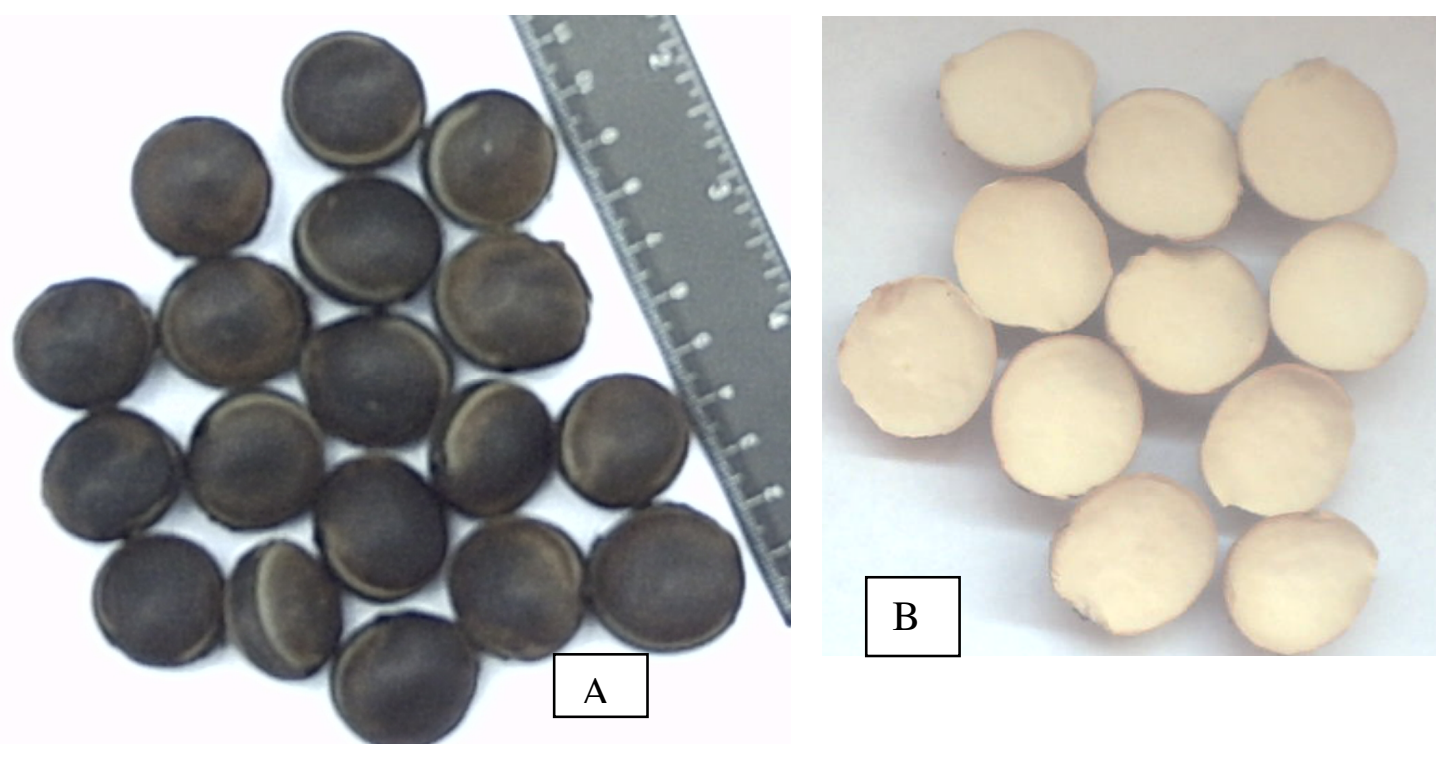

Fig. 1: M. flagellipes seeds (A), endosperm cotyledons (B)

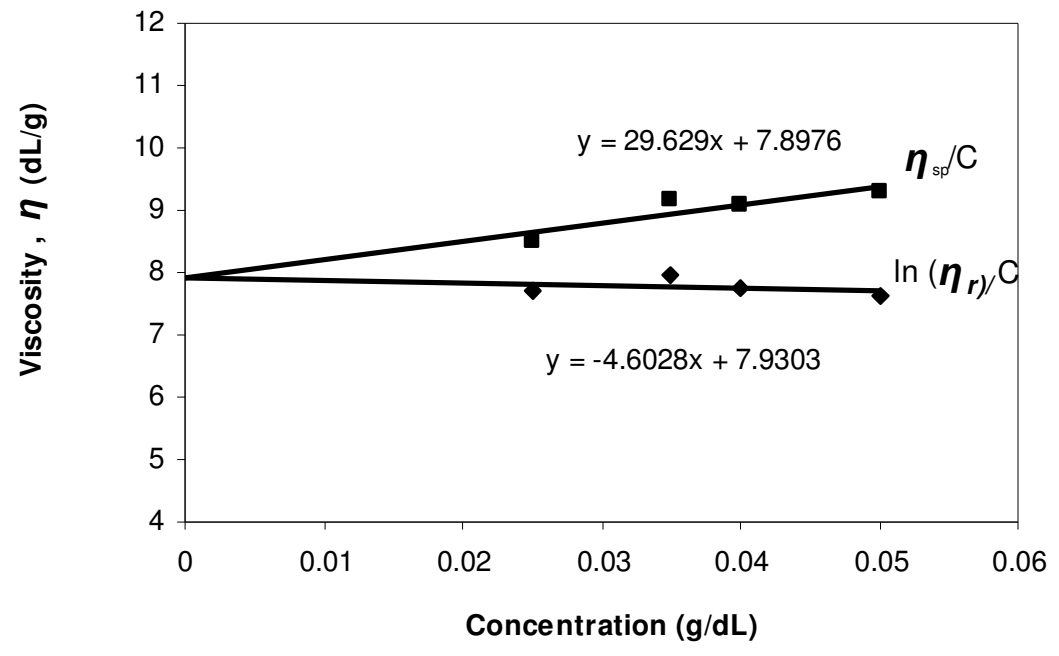

Fig.2. Determination of the intrinsic viscosity of $M$.

flagellipes gum 


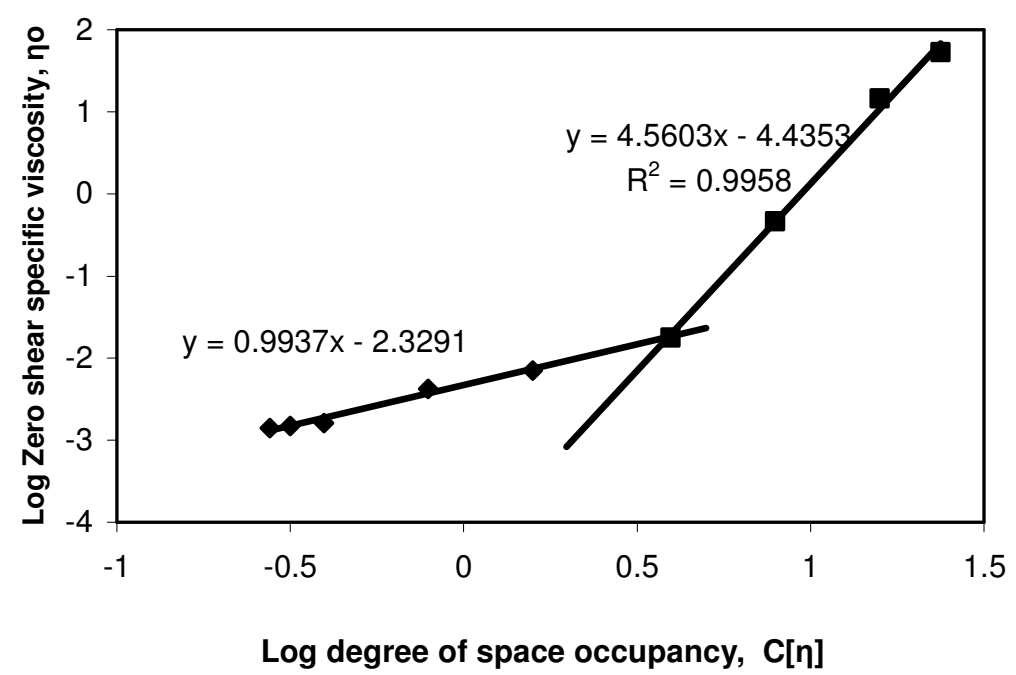

Fig.3a: Zero shear pecific viscosity versus Degree of spaceoccupancy of $M$. flagellipes gum

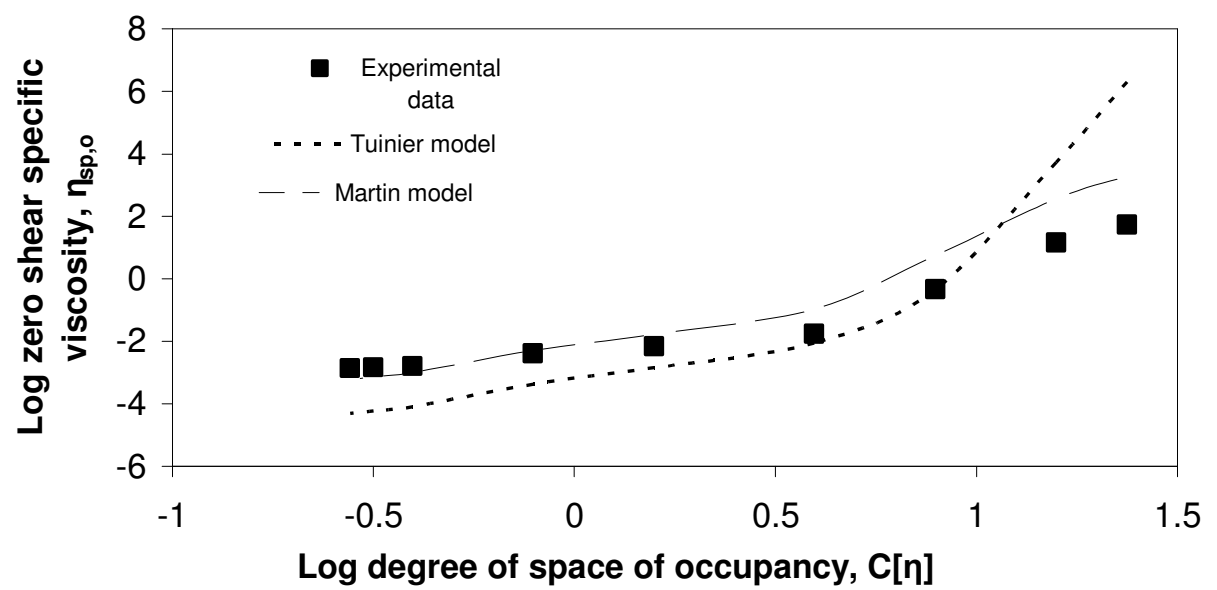

Figure 3: Log zero shear specific viscosity $\eta_{s p, o}$ versus Log degree of occupancy, C[n] 


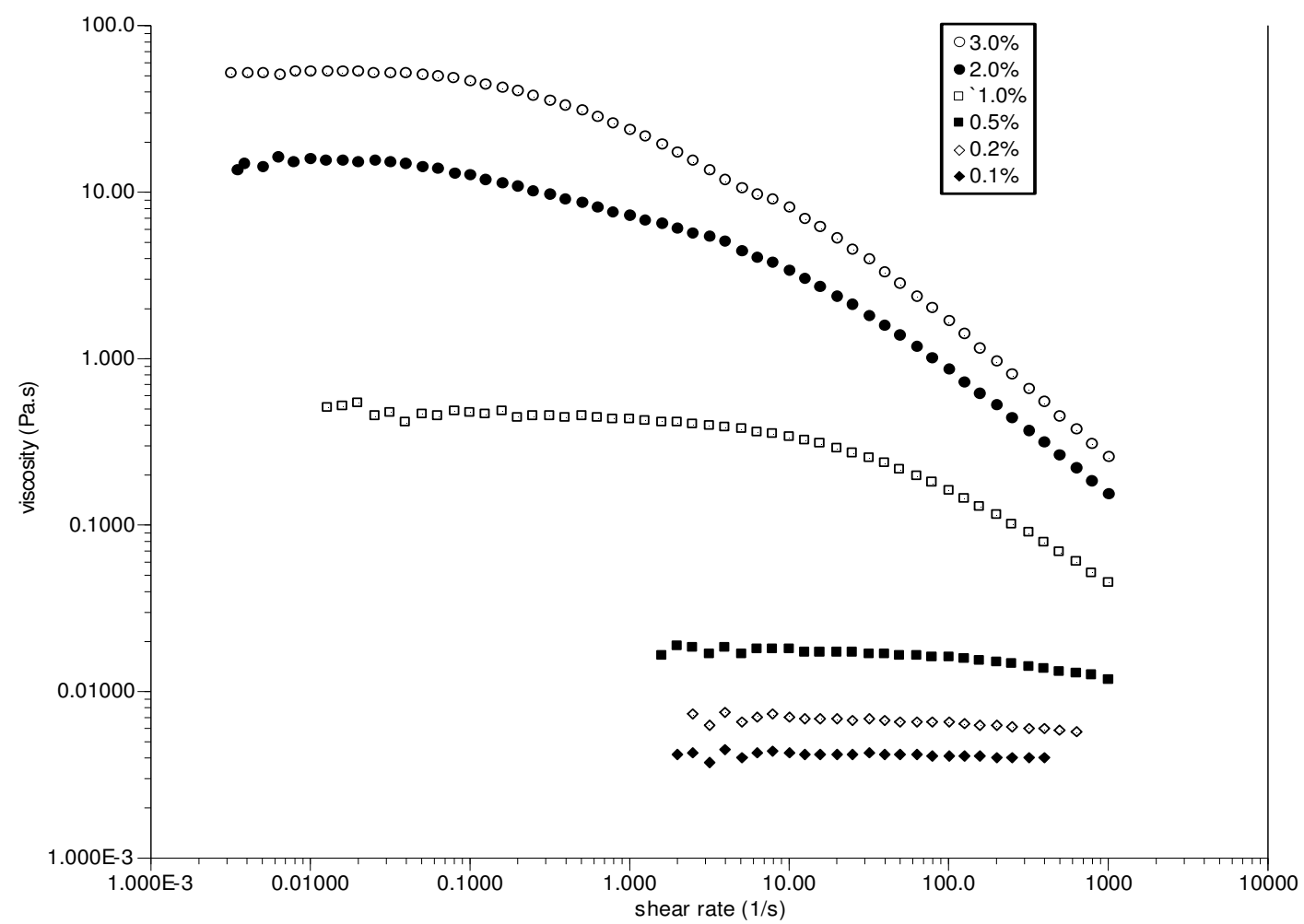

Fig.4: Viscosity-shear rate profiles for different concentrations of M. flagellipes gum 


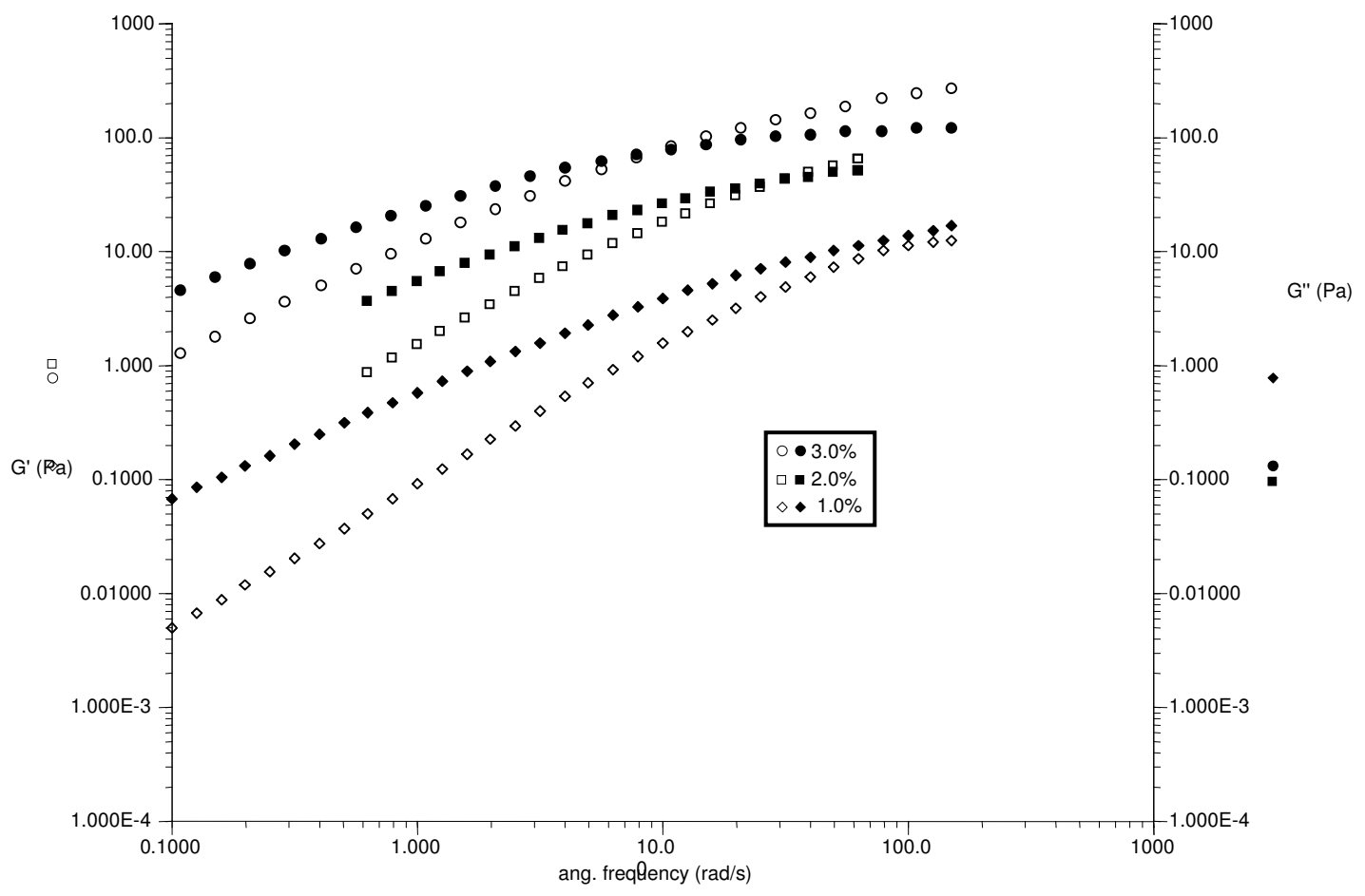

Fig. 5: Frequency sweep showing G' and G" for different concentrations of $M$. flagellipes gum

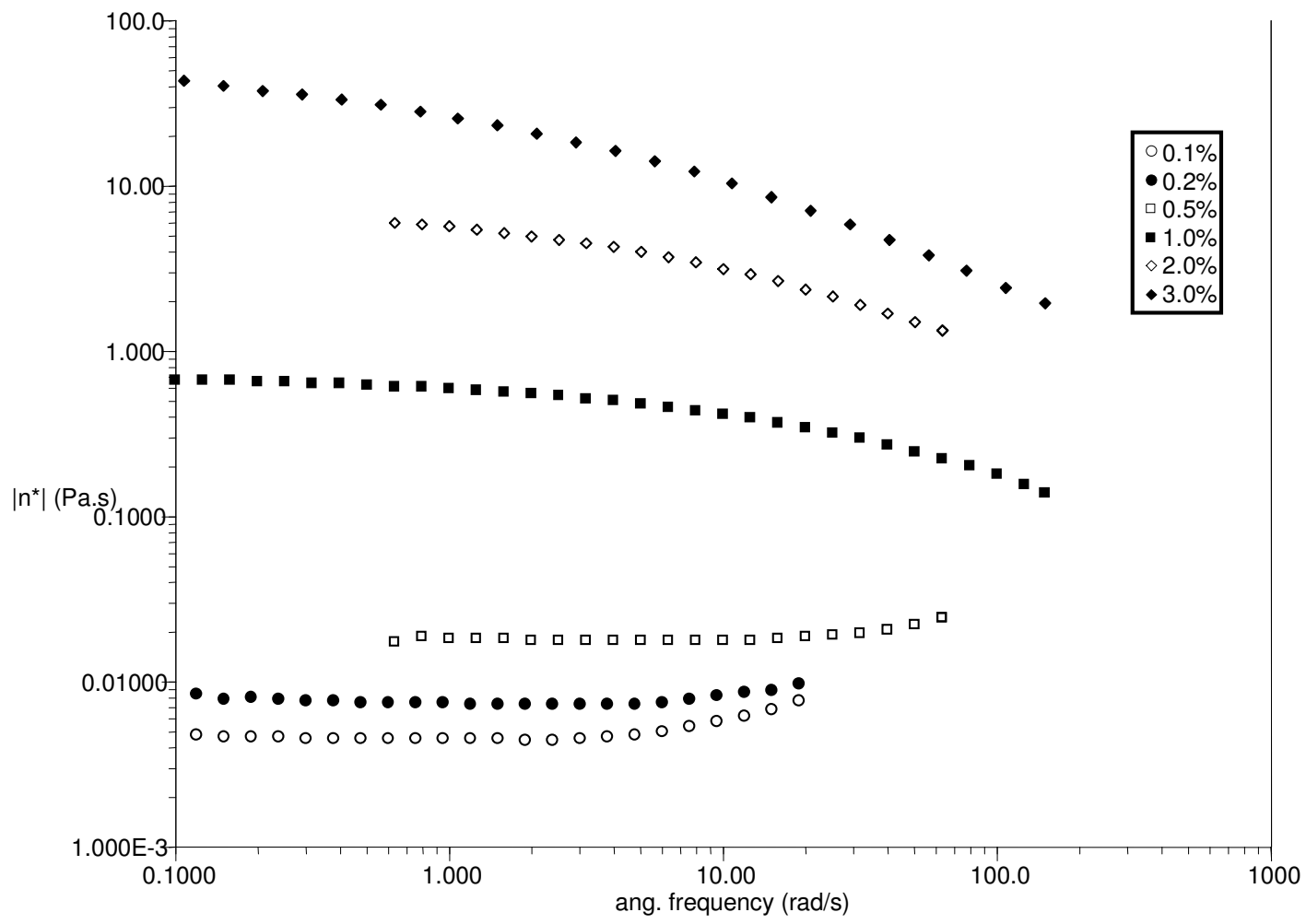

Fig. 6: Frequency sweep showing dynamic viscosity $/ n^{\star} /$ for different concentrations of $M$. flagellipes gum 


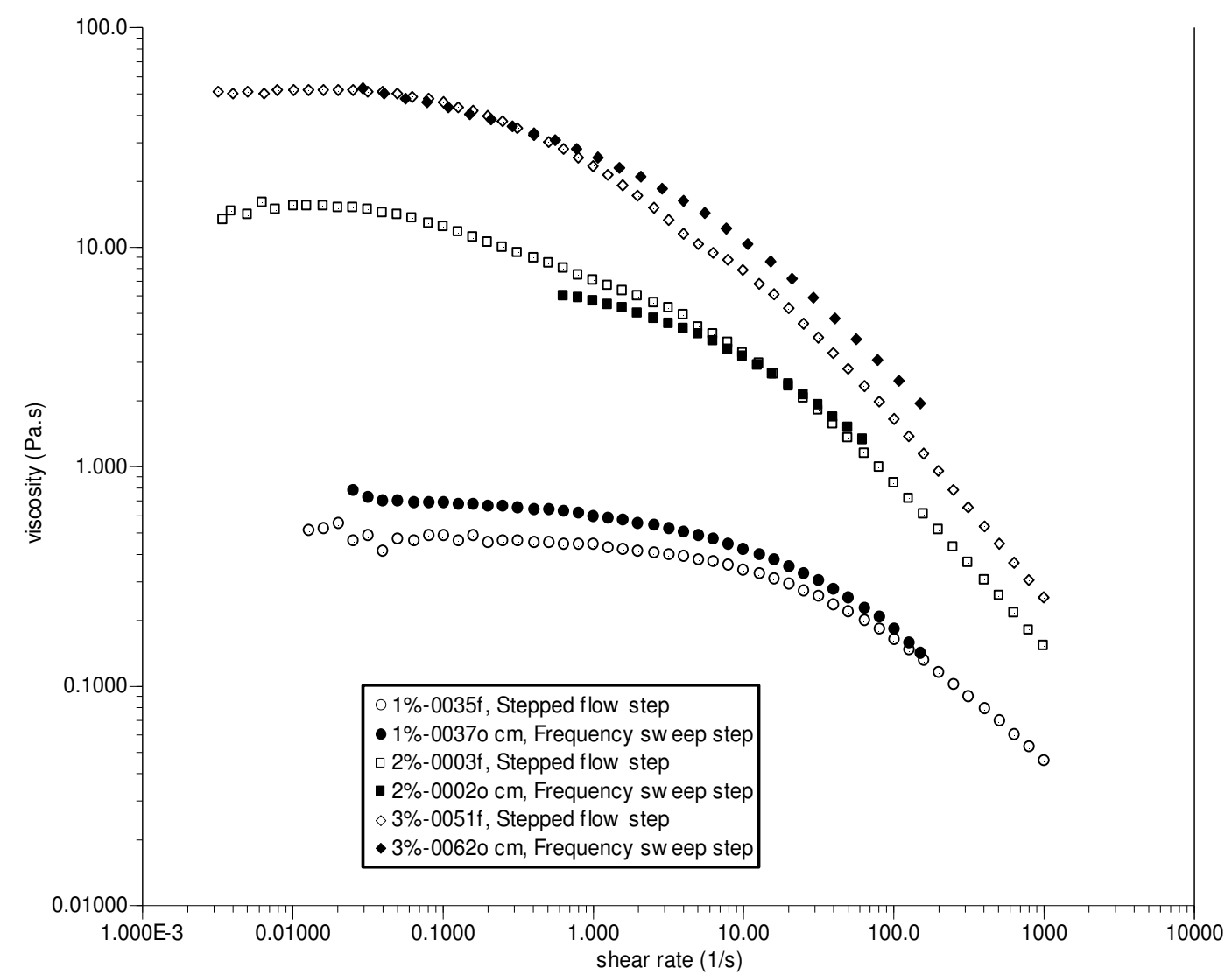

Figure 7: Cox-Merz plots, superimposition of $\log \eta(\bar{y})$ and $\log \eta *(\omega)$

Table 1: Physical composition of $M$. flagellipes seed ${ }^{\mathrm{a}}$

\begin{tabular}{lcc}
\hline Composition & Range & Mean \\
\hline Hull $(\%)$ & $25.24-53.27$ & $32.85 \pm 10.15$ \\
Endosperm $(\%)$ & $46.73-74.76$ & $67.15 \pm 10.15$ \\
Germ $(\%)$ & - & - \\
\hline
\end{tabular}

$\stackrel{a}{=}$ mean for nine seeds $\pm \mathrm{SD}$ 
Table 2: Yield and composition of $M$. flagellipes gum

$\begin{array}{ll}\text { Yield }(\%)^{\mathrm{a}} & 32.6 \pm 1.97 \\ \text { Carbon }(\%) & 39.253 \\ \text { Hydrogen }(\%) & 6.425 \\ \text { Nitrogen }(\%) & 1.873 \\ { }^{\mathrm{a}}=\text { mean of triplicate determinations } \pm \text { SD } & \end{array}$

Table 3: Rheological model-fitted characteristics of $M$. flagellipes gum.

\begin{tabular}{lllllll}
\hline $\begin{array}{l}\text { Gum conc. } \\
\%(\mathrm{w} / \mathrm{v})\end{array}$ & $\begin{array}{l}\text { Rheological } \\
\text { Models }\end{array}$ & $\eta_{\mathrm{o}}(\mathrm{Pa} . \mathrm{s})$ & $\eta_{\infty}(\mathrm{Pa} . \mathrm{s})$ & $\tau(\mathrm{s})$ & $\mathrm{K}$ & $\mathrm{S} . \mathrm{E}$ \\
\hline & & & & & \\
3.0 & Cross & 53.30 & $1.868 \mathrm{E}-7$ & 1.80 & 0.7370 & 12.41 \\
2.0 & Cross & 14.62 & $8.709 \mathrm{E}-8$ & 0.7196 & 0.6689 & 18.89 \\
1.0 & Cross & 0.12413 & $4.356 \mathrm{E}-3$ & $4.33 \mathrm{E}-3$ & 0.7202 & 20.16 \\
0.5 & Cross & 0.01775 & $8.359 \mathrm{E}-3$ & $1.756 \mathrm{E}-3$ & 0.8417 & 57.10 \\
0.2 & Newtonian & $5.862 \mathrm{E}-3$ & - & - & - & 12.2 \\
0.1 & Newtonian & $4.001 \mathrm{E}-3$ & - & - & - & 4.12 \\
\hline
\end{tabular}


Table 4: Analysis result of curve of $\log \eta_{\mathrm{sp}}$ versus $\log \mathrm{C}[\eta]$ for M. flagellipes gum concentrations

\begin{tabular}{ll}
{$[\eta](\mathrm{dL} / \mathrm{g})$} & 7.9 \\
$\log \mathrm{C}^{*}[\eta]$ & 0.6 \\
$\mathrm{C}^{*}[\eta]$ & 3.98 \\
$\mathrm{C}^{*}(\mathrm{~g} / \mathrm{dL})$ & 0.50 \\
$\log \eta_{\mathrm{sp}}$ at $\mathrm{C}^{*}$ & -1.75 \\
$\eta_{\mathrm{sp}}$ at $\mathrm{C}^{*}($ Pa.s $)$ & 0.018 \\
Slope below $\mathrm{C}^{*}$ & 1.0 \\
Slope above $\mathrm{C}^{*}$ & 4.6 \\
\hline
\end{tabular}

